\title{
The Globalisation of Macrobiotics as Culinary Tourism and Culinary Nostalgia
}

\author{
Nancy Stalker
}

\begin{abstract}
This article examines the malleable identity of the macrobiotic diet, a largely vegetarian regime focused on brown rice and traditional Japanese foods, popularly known as a diet that could cure diseases, including cancer. It argues that the historical and geographical context of macrobiotics helped determine its appeal, i.e. initial interest in the West was driven by a sense of 'culinary tourism' while Japanese contemporary interest in macrobiotics is informed by a sense of 'culinary nostalgia.'
\end{abstract}

\section{Keywords}

Macrobiotics, Japanese food, culinary tourism, culinary nostalgia, George Ohsawa, Michio Kushi

\section{Introduction}

Two attractive young women sit at a swanky café in one of Tokyo's upscale neighborhoods enjoying a luscious afternoon 'cake set'. This is a very typical scene, yet, in recent years, looking closer, one might see that the cakes are not made with butter, eggs or milk but instead use tofu, beans, and coconut or soy milk. The cakes are called 'macrobiotic'.

In 1825, French gastronome Jean Anthelme Brillat Savarin famously wrote: 'Tell me what you eat, and I will tell you who you are.' He meant that people construct and sustain their identities through everyday acts involving food preparation and consumption. Food encodes meanings and reinforces bonds among social classes, ethnicities, genders, regional or national identities and religious groups, among other things. ${ }^{1}$ According to food historian Felipe Fernandez-Armesto, quite simply, nothing matters more to most people for most of the time than food. ${ }^{2}$ Nevertheless the same foods often hold different meanings and identities for different peoples. In this paper, I discuss the

${ }^{1}$ LeBesco and Naccarato 2008 (eds) 2008, p. 1 and Gabaccia 1998, p. 6.

2 Fernandez-Armesto 2001, p. 16. 
macrobiotic diet, a low-fat, largely vegetarian regime focused on whole grains, especially brown rice, and featuring Japanese traditional foods such as miso, seaweeds and pickled plums, known as umeboshi. The term macrobiotics was first coined by Christoph Wilhelm Hufeland, an eighteenth-century German physician and first popularised by Sakurazawa Yukikazu (1893-1966), known in the West as George Ohsawa (aka Sakurazawa Nyôichi.) When he first popularised macrobiotics in the West in the late 1950s, Ohsawa claimed that his dietary regime would cure all disease within ten days, whether cancer, epilepsy, diabetes, mental illness or even leprosy. During his lifetime, Ohsawa published over three hundred books and delivered over seven thousand lectures on macrobiotics in thirty countries. While both the diet and its claims have been tempered, it never really achieved mass support in the West, although celebrity followership from stars like John Lennon, Yoko Ono and Gwyneth Paltrow attracted media attention. ${ }^{3}$ The stark contrast between the 1960 s' $^{\prime}$ countercultural diet in the West and its twenty-first century incarnation as fashionable luxury foods in Japan presents a fascinating case of the malleable identity of health food regimes.

In this paper, I do not analyze or comment on the efficacy or lack of efficacy of the macrobiotic diet as a tool for healing. Instead, I review texts and cookbooks from both Japan and the USA to focus on how historical and geographical context help to shape the meaning and identity of macrobiotics. As noted by Arjun Appadurai, cookbooks combine practicality with pleasure and are an effective vehicle for reflecting shifts in 'the boundaries of edibility' and the 'structure of domestic ideologies'. ${ }^{4}$ In short, macrobiotics texts reveal that it is not simply a diet, but an 'edible ideology' with a malleable message according to audience, location and era. ${ }^{5}$

Putting health claims aside, I argue that macrobiotics' initial appeal in the West was driven by a sense of 'culinary tourism', while more recent Japanese interest was initially most informed by a sense of 'culinary nostalgia', although it is currently also a kind of consumerist fad. Culinary tourism is the practice of exploring differing food traditions as a traveler explores new landscapes or spaces. It differs from the simple act of eating because desire for food is driven by curiosity and longing to experience difference rather than by physical needs of hunger or satiety. ${ }^{6}$ In contrast, culinary nostalgia is driven by desire for dif-

3 While it is difficult to calculate its level of popularity, authors have estimated that by the mid-1980s there were 100000 to 500000 'true' macrobiotics and another two million 'semi' macrobiotics. Thirty of fifty states in the USA had macrobiotic centers of some form.

4 Appadurai 1988, p. 3.

5 This term comes from LeBesco and Naccarato.

${ }^{6}$ Long (ed.) 2004, pp. 6, 59. 
ferent temporalities. It invokes familiar and comforting foods from the past that provide relief from alienation and provokes a desire to preserve native cultures and values. ${ }^{7}$ These two concepts can be seen as the opposite poles of human eating habits, which, according to Donna Gabbaccia, originate in a 'paradoxical and perhaps universal tension between a preference for the culinarily familiar and the equally human pursuit of pleasure in the forms of culinary novelty, creativity and variety'. ${ }^{8}$

The popularity of macrobiotics peaked in different eras in Japan and the West, and it attracted different audiences. Macrobiotics first gained a Western following in the late 1950s among beatnik and then hippie cultures seeking opportunities to reject mainstream lifestyles. In the 1950s and 1960s, new technologies for storing and transporting food, along with high levels of disposable income and more leisure time, contributed to a proliferation of dining options, from TV dinners to McDonalds, which was founded in 1954. In the atmosphere of 'Cold War Orientalism', going out for Chinese food was regarded as culturally equivalent to attending art house movies. ${ }^{9}$ The Japanese macrobiotic diet filled a niche for culinary rebellion-exotic, ascetic, 'natural' and requiring, rather than eliminating, labor and sacrifice. According to the New York Times, Ohsawa's followers tended to be in their early 20s, white, middle-class ex-drug users, 'slightly righteous and more than a little disenchanted with contemporary American life'. ${ }^{10}$

Meanwhile, in Japan, the diet known as 'makurobiotikku' or 'makurobi', transliterations from the English name, did not really achieve recognition until the 1990s, and has only recently reached critical mass, primarily among housewives seeking healthy and economic meals for their families, but also among the fashionable young female consumers mentioned above. ${ }^{11}$

The recent volume Asian Medicine and Globalization, interrogated the tensions between the proclaimed universal or transnational applicability of Asian health systems and their nationalistic identities, their association with

7 Caldwell 2006, pp. 97-113.

${ }^{8}$ Gabaccia 1998, p. 8.

9 Abrams 2008, pp. 105-20.

${ }_{10}$ Alexander 1972, p. 94.

11 An examination of the World Cat database to compare Japanese books with the keyword 'Makurobiotikku' with English and French works, demonstrates clearly that peak Japanese interest lagged behind peak Western interest by about a decade. English and French-language publications begin to be visible in the 1970s with 75 and 15, respectively. Publications peaked in the 1980s, with 180 in English and 35 in French. Popularity then dropped off significantly in French works, but 165 more books were published in English in the 1990s and in the current decade. In comparison, in Japan during the 1970s and 1980s, a total of just five macrobiotic titles were published, and only nine in the 1990s. But since 2001, there have been 82 titles published, with a peak of 27 titles in 2004 . 
particular nation-states. ${ }^{12}$ Macrobiotics provides an interesting illustration of these tensions. A health system created by a Japanese man featuring Japanese foods and philosophy, it was, nevertheless, popularised outside of that bounded nation-state framework via Japan's postwar transnational interactions with the geopolitically hegemonic USA. When macrobiotics moved from Japan across the Pacific Ocean, it not only retained but sharpened its rigid Japaneseness as a means of attracting Western audiences enamored with the exotic Orient. When it recently traveled back to Japan, the aspect of culinary tourism associated with novel foods and food philosophies was not a factor, as the foods were common in the everyday pantries and the philosophies resonated with folk worldviews. Instead, in Japan, macrobiotics became a forum for nostalgia, for self-congratulation on Western adoption of Japanese culture, and for indulging in expensive consumerist pastimes.

Ohsawa's original formulation of the diet was deeply grounded in his own personal philosophy, a mélange of Daoist notions of yin and yang, nutritional theory and Japanese folk wisdom about food and food etiquette. Ohsawa referred to balance of yin and yang to as the 'unique principle' and believed that all phenomena could be analyzed in terms of yin and yang. ${ }^{13}$ Applied to dietary principles, the basic idea was that if one understands the yin or yang qualities of different kinds of foods, along with one's own personal yin or yang qualities, interpreted via physiognomy, one could eat in a method that produced a balance of the two forces, resulting in health and freedom from disease. Ohsawa claimed that simple vegetarianism, without the guidance of his yin-yang philosophy, 'does not suffice.... and can descend into mere sentimentalism. ${ }^{14}$

The yin and yang qualities of foods were affected by a number of factors including their species, season, method of growing, cooking and storage. Yin foods were soft and/or watery, like cucumbers, mushrooms, shellfish or yogurt. They grew quickly, straight up into the air like corn and wheat or sideways under the ground, like burdock. They were rich in potassium, quick to cook, and grew well in warm or hot climates. Nearly all fruits were very yin, but tropical fruits like bananas and pineapple were even more so. Eating yin foods made the body colder, softer, docile, slower, and in need of more sleep. Yang foods in contrast were hard and contained little water. They grew sideways above ground and straight down below ground. They were rich in sodium,

12 Alter 2005, pp. 1-6.

${ }^{13}$ His philosophy was first elaborated in 1931 in the work Le Principe Unique de la Philosophie et de la Science d'extreme Oriente, published in Japan in 1936 as Muso Genri, eki: jitsuyo benshoho.

${ }_{14}$ Alexander 2005, p. 90. 
required a long time to cook and grew well in cool or cold climates. Eating yang foods like legumes, animal products and daikon radishes, made the body warmer, harder, quicker, more short-tempered and less needful of sleep.

Ohsawa's claim of a ten-day cure-all was based in his belief that the body's blood was completely 'renewed' every ten days to two months. He believed all disease was the result of errors in judgment and behaviors due to ignorance about yin and yang principles. Curing disease was simply a matter of changing behaviors like eating and drinking that upset the balance of nature. Ohsawa's macrobiotic healing eschewed surgery and modern medicine. He proudly proclaimed: 'Our pharmacy is the kitchen.' ${ }^{15}$ Whole grains, especially brown rice, millet and buckwheat should comprise at least half of the diet. Ohsawa provided a range of ten different combinations of grains, vegetables and other whole foods, but advocated the strictest diet of one hundred percent whole grains, called Diet No. 7, for beginners to jumpstart the healing process and provide the most rapid results. ${ }^{16}$ Under Ohsawa's regime, one should eat and drink the minimum possible, severely controlling water intake so as not to overtax the kidneys. One should also chew all foods at least fifty and ideally up to one hundred times to soften the foods and enhance the taste. ${ }^{17}$ Despite the limited liquid intake, he advocated heavy consumption of sodium-rich yang foods like soy sauce, miso, sesame salt (gomashio) and pickled plums or radishes.

As macrobiotics gained momentum in the West, critics of the diet emerged. Those adherents who had not recovered from disease denounced Ohsawa. He claimed, in turn, that not all individuals could be healed through his regime. Those seeking a quick cure but who were arrogant and unwilling to apply the underlying philosophy, which involved admitting their own faults and ignorance and recognizing the 'True Order of the Universe', had 'no right to criticise my teaching'. ${ }^{18}$ In early 1965, a young woman named Beth Ann Simon died of malnutrition and dehydration under Diet No. 7. Macrobiotics came under scrutiny as 'the killer diet' as the US Food and Drug Administration closed the New York center and the Ohsawa foundation, and the American Medical Association condemned the diet as 'dangerous. ${ }^{19}$ Ohsawa died the following year and, while the movement lost its initial momentum, his

15 Ferre (ed.) 1994, p. 48.

16 Ohsawa 1959, pp. 22-4.

17 Ohsawa 1959, pp. 22-4. This practice may have arisen in conjunction with the many periods of famine in nineteenth-century Japan, where each mouthful of food needed to be extended as much as possible.

${ }_{18}$ Ferre (ed.) 1994, pp. 52-62.

19 New York Times, 12 November 1965, mentioned by Kotzsch 1985, p. 167. 
primary disciples Michio Kushi and Herman Aihara helped build macrobiotic communities in major cities in the USA and Europe through the 1970s. It was not until the 1980s, however, that macrobiotics began to reach broader general audiences. A key factor was a popular book by Dr. Anthony Sattilaro entitled Recalled by Life: The Story of My Recovery from Cancer. ${ }^{20}$ Satillaro, president of Methodist Hospital in Philadelphia, primarily credited the macrobiotic diet for curing his prostate cancer. ${ }^{21}$ The book was translated into numerous languages and interest in macrobiotics as a potential cure for cancer surged.

\section{Culinary Tourism}

Putting aside this desire for a medical cure, however, I describe the Western relationship with macrobiotics as culinary tourism because it often emphasized exoticism and semi-mystical practices like physiognomy and it fetishised foreign macrobiotic foods. Culinary tourism is premised on the pleasure to be found in the consumption of an exoticised, commodified other. ${ }^{22}$ Macrobiotic foods, practices and philosophies were novel and exciting for Westerners, inviting fantasies of new experience and attainment through consumption. Many of the exoticised, Orientalised qualities were in fact promoted by Ohsawa. He boldly drew associations between his diet and various aspects of Asian culture that had captured the Western imagination. He unabashedly made claims like one 'can find Shangri-la and Satori' through macrobiotics, which was 'in reality a kind of Aladdin's lamp, a Flying Carpet with which you can realise your fondest dreams..$^{23}$

Ohsawa fancied his mission to be a cultural broker, an interpreter of the East for the West. During his sojourns abroad, he capitalised on aspects of Japanese culture fashionable among Westerners. He wrote books on ikebana, the art of flower arrangement, and on Judo as a platform for his own theories, injecting his views on health, medicine and world peace. In 1931, while in France, he published his first work on Yin-Yang theory, medicine and nutrition (Le Principe Unique de la Philosophie et de la Science d'extreme Oriente). In this text, in an attempt to appeal to French audiences enamored with Buddhism, he included an appendix with two classical Buddhist texts. ${ }^{24}$ In short, he freely and often misleadingly took advantage of Western interest in tradi-

20 Sattilaro 1982.

${ }^{21}$ Kotzsch 1985, p. 176.

22 Hooks 1999, p. 116.

23 Ohsawa 1959, p. 15.

24 These were the Heart Sutra and the Tannisho of the True Pure Land sect. 
tional Japanese and 'Oriental' culture to gain greater credibility for his own work. $^{25}$

Ohsawa's first book in English, entitled Zen Macrobiotics was rapidly compiled in 1959 in preparation for his first trip to the USA. It contained a hodgepodge of Ohsawa's philosophy, recipes, and medical treatments alongside criticism of Western civilisation. ${ }^{26}$ In the text, Ohsawa conflated macrobiotics with all East Asian religious traditions, claiming his approach was 'five thousand years old' and that Confucius and Buddha, among other sages, taught macrobiotics. ${ }^{27}$ The association with Zen was, again, a conscious attempt to capitalise on the popularity of Zen in America due to the work of beat generation poets and writers like Jack Kerouac. Ohsawa claimed that the macrobiotic diet was equivalent to the shojin ryōri vegetarian diet of Zen monasteries and that both promoted enlightenment. Ohsawa's embrace of Zen contradicted his earlier views published in Le Livre de Judo, where he criticised 'socalled Buddhists who charm the masses' and attract 'the ignorant majority, empty-minded after the fashion of Zen'. ${ }^{28}$

Another aspect of macrobiotics that emphasized difference from the West was its use of physiognomy as a diagnostic tool. Ohsawa gained mass media attention in the USA with his claim that he predicted President John F. Kennedy's tragic death through his condition of sanpaku. ${ }^{29}$ Meaning 'three whites' in Japanese, this word describes eyes with whites showing beneath the iris and supposedly indicates individuals who are destined for tragedy but can change their fate if they heal themselves through macrobiotics. A version of Zen Macrobiotics, re-edited by journalist and follower William Duffy, entitled You Are All Sanpaku, provocatively displayed the eyes of twelve famous individuals, including Marilyn Monroe, J. Paul Getty, JFK and Bobby Kennedy, who all suffered from this condition. The concept of sanpaku is part of Japanese health-related folklore. Ohsawa and his Japanese disciples drew extensively on popular Japanese folk medical knowledge, commonsense and physiognomy to diagnose disease. Health imbalances could be determined in numerous ways, from sanpaku to facial lines, the shape of lips, the degree of baldness and even one's pattern of wearing down shoes. ${ }^{30}$ Facial proportions and the shape of different features indicate whether one's basic personality is

25 Kotzsch 1985, pp. 54-62.

26 Kotzsch 1985, pp. 127-33.

27 Ohsawa 1959, 'preface'.

28 Ohsawa 1951, p. 122.

29 New York Herald Tribune article mentioned in Dufty (ed.) 1965.

30 Aihara 1985, pp. 39-41 and Kushi 1983. Kushi, Ohsawa's prime disciple, explicated the concepts of 'Oriental diagnosis' through examining not only the eyes, mouth and hair, but also voice, handwriting and palmistry. Key tenets of macrobiotic physiognomy included that a person's constitution is established in the womb and is heavily influenced by the mother's diet. 
yin or yang. Facial elements that are more protruding are yin and those that are flatter or more indented are yang. A person with yin ears that stick out will have narrow perspectives. Those with long ears close to the head have sound judgment. ${ }^{31}$ Such physiognomic approaches to health likely provided a novel and exotic experience for Western adherents accustomed to modern medical diagnosis and treatment, as apparent in 1972 New York Times story on macrobiotics that featured a physiognomic analysis of Richard Nixon.

A final factor in considering Western interest in macrobiotics as a form of culinary tourism is the fetishisation of Japanese traditional foods. Ingredients, like miso, different seaweeds, umeboshi, gomashio sesame salt and azuki beans, were commonly found in Japanese kitchens but were rare commodities that embodied difference from mainstream food lifestyles in the USA. Advocates claimed many of these foods carried extraordinary healing properties based on anecdotal evidence, e.g. miso treated radiation sickness after the atomic bombing of Nagasaki and umeboshi stops diarrhea and cures hangovers. ${ }^{32}$ For Western followers, these unfamiliar food items became an important symbol of countercultural macrobiotic identity. Despite the fundamental macrobiotic tenet of eating locally produced foods (an issue I will return to later), Americans took pleasure in consuming these difficult-to-obtain, unfamiliar foods. The importation of these foods from Japan, alongside recommended tools like bamboo rice paddles and tea strainers, served as a source of financial support for the movement as food companies emerged on both coasts including Chico-san in California, established by Herman Aihara in 1960 and Michio Kushi's Erewhon in Boston.

\section{Culinary Nostalgia}

Turning to the examination of macrobiotic popularity in Japan as a form of culinary nostalgia, I examine three factors: reassessment of the historical Westernisation of the Japanese diet, links with Japanese folk wisdom, and the role of gender in macrobiotics.

Japanese macrobiotic cookbooks and texts often cite the increased consumption of beef, pork, butter, cheese, milk and sugar in Japan. Compared to 1950 the Japanese eat nine times more meat, seven times more eggs and a whopping nineteen times more dairy products. ${ }^{33}$ There is an ethnocentric

\footnotetext{
31 Kushi 1983, p. 35.

32 Aihara 1985, pp. 112-15.

33 Genmai de ochaku daietto 2006, pp. 4-12. Compared with the 1920s and 1930s, contemporary Japanese consume 13 times more meat and 28 times more dairy produce.
} 
tinge to many texts that attribute health problems like high blood pressure and diabetes, along with lesser issues like stiff shoulders, heartburn and the tendency to chill easily to this Westernisation of the diet. ${ }^{34}$ Consumption of white flour and refined sugar over the long-term was even said to create individuals who were suicidal and prone to being criminals or bullies. ${ }^{35}$ One author recommended inducing sweating and ingesting brown rice products immediately after indulging in a foreign meal to help expel toxins. ${ }^{36}$

Dietary Westernisation followed the forced opening of Japan in the midnineteenth century. Western foods and material culture began to gain acceptance and this trend sharply accelerated during the postwar period. Following the Iwakura Mission, launched in 1871, which sought to better understand the civilisation and culture of the West, Prince Iwakura Tomomi, mandated Westernisation of the Japanese diet. From the Emperor downwards, all were urged to increase their consumption of meat, despite traditional taboos against meat eating, in order to be more like Westerners. ${ }^{37}$ French cuisine was dictated for all Imperial palace public occasions. ${ }^{38}$ In contrast, the Japanese pre-modern diet, even among wealthy urbanites, was generally monotonous with little variation, consisting of rice, pickles, miso soup and a limited rotation of side dishes based on seasonally available ingredients.

It was actually the military that played a leading role in initially furthering public nutritional knowledge in the Meiji period. One national slogan of the time was 'Rich Country, Strong Army' ( fukoku kyōhei) and the army and navy were concerned over the consequences of malnutrition among soldiers. They added meat, wheat and milk to military diets. The Meiji government fostered the new meat industry, helped to establish canneries and encouraged the production of non-traditional vegetables including carrots, lettuce and parsley. ${ }^{39}$ Fierce debates erupted about whether Western or Japanese cuisine was more

34 Ibid.

${ }^{35}$ www.macro-biotic.jp, accessed 10 October 2008.

36 Okada 2007, pp. 61-7.

37 Akiba 1997, pp. 131-45. The taboos against the eating of meat dated back to a seventh century imperial rescript prohibiting meat eating as a means of protecting livestock needed for farming. Over time, the Buddhist concept of reincarnation and legal decrees against meat eating were linked, so that it was commonly believed that those who ate the meat of four legged animals would be reborn as one. People who had eaten meat were considered unclean, and disqualified from participating in Shinto rituals or visiting important Shinto shrines.

${ }_{38} \mathrm{Ibid}$. Returning from his tour through Europe and the USA in the early 1870 s, Prince Iwakura Tomomi mandated complete transformation of the Imperial household. In addition to diet, the emperor exchanged his plucked eyebrows and blackened teeth for a Westernised countenance, tatami mats were replaced with carpets.

39 Cwiertka 2006, p. 14. 
appropriate for building troop strength and stamina. ${ }^{40}$ The well-known writer Mori Ōgai, born Mori Rintarō, was a military surgeon engaged in the reform of military catering and strongly rejected the idea of Japanese armed forces becoming dependant on Western food products. ${ }^{41}$ In order to secure inexpensive domestic sources of field rations that had a long shelf life, military brass cooperated with the fledgling food processing and canning industries. They created a hybrid cuisine consisting of rice as a staple with cheap and caloric Western side dishes like potatoes, curries and croquettes. One popular hybrid dish was canned beef simmered in soy sauce. By the time of the RussoJapanese war in 1904, such domestic canned products were ubiquitous military supplies. ${ }^{42}$

The macrobiotic movement was actually rooted in these military concerns. Ohsawa closely modeled his diet on the works of Ishizuka Sagen (1851-1909), a medical doctor who served in the Japanese army during the Meiji period, beginning in 1873. Ishizuka was influenced by both Chinese classical texts, like the fifth century BC Yellow Emperor's Classic of Internal Medicine, (Huangdi neishing) and by works on physiognomy and diet by Mizuno Nanboku. ${ }^{43}$ In the army, he invented useful medical items, such as tweezers and stretchers made from bamboo, and foods with long shelf lives, like dehydrated vegetables and hardtack. Ishizuka experimented with different diets to see which helped wounded soldiers to recover fastest. He believed that rapid absorption of Western culture and diet had resulted in Japan's physical and spiritual decline. He saw diseases like tuberculosis and beriberi steadily increasing, alongside egotism and materialism, and advocated a return to traditional eating patterns stressing unpolished rice and other whole grains and organic native foods like sea vegetables and beans. Ishizuka began publishing articles in medical journals in 1894 and began to attract a mass audience with popular book publications in $1898 .{ }^{44} \mathrm{He}$ was soon accepting patients from throughout Japan at his home and clinic in the Ichigaya area of Tokyo.

Despite his nativist orientation, Ishizuka turned to the language of chemistry and Western science in his work on nutritional theory, claiming that a person's health was based on the balance between sodium and potassium

\footnotetext{
${ }^{40}$ Cwiertka 2006, p. 65.

41 Ibid.

42 Cwiertka 2006, pp. 58-64, 84, 120. On the role of the military in modernizing food supplies in WWI Europe, see Kingsbury 2008.

43 Works by and on Ishizuka and Nanboku have recently been re-released by different publishers. On Mizuno and his works, see Sawada 2004.

${ }^{44}$ Ishizuka 1898.
} 
obtained through diet. Individuals were dominated by one of these elements, dictating their physical and psychological characteristics. He also stressed the role of geography, climate and physical activity in determining proper diet.

The Shokuyōkai, or Food Cure Society, was formed in 1907 based on Ishizuka's teachings. Ohsawa joined the society in 1911 and in 1923 climbed to the position of editor of its magazine. His writings became increasingly antiWestern, deriding meat-eating culture and its crass materialism while elevating Eastern medicine and philosophy. He began to apply the Daoist concepts and terminology of yin and yang to substitute for Ishizuka's potassium ( $y \mathrm{in}$ ) and sodium (yang). Many in the Shokuyōkai society believed that Ohsawa's departures from the original teachings were inappropriate and he was asked to resign. ${ }^{45}$

Ohsawa continued to try to promote his dietary ideas throughout the wartime years, but it was not until the postwar period that he began to attract real attention, albeit abroad. ${ }^{46}$ In Japan, in the era following Japan's defeat and subsequent Americanisation through occupation, there was little popular appetite for his simple, old-fashioned diet of brown rice and pickles. Ohsawa and his wife Lima set off on a sojourn that he dubbed 'the world journey of the penniless Samurai' that lasted from 1953 to 1966 and helped him launch his movement in the West. ${ }^{47}$ Success abroad eventually brought reimportation of the diet to Japan, where it represented a triumphant return of traditional, homestyle foods that met with approval with from the West.

Many of Ohsawa and Ishizuka’s beliefs about food came from Japanese folk wisdom, which was in turn based on a variety of Buddhist and Confucian teachings. Kaibara Ekken (1630-1714), a popular seventeenth century NeoConfucian philosopher wrote at length on food issues: advocating rice as a staple, limiting oneself to seasonal vegetables and avoiding meat and overeating. ${ }^{48}$ Ohsawa incorporated these practices and beliefs into twentieth century macrobiotics.

Two fundamental, and oft-repeated aphorisms of the Japanese macrobiotic movement are Shindō fuji (body and earth are not two, but one) and Ichibutsu zentai (use the whole body of each item). These aphorisms, emphasizing local food and economizing are derived from folk knowledge on food and frugality.

\footnotetext{
45 Kotzsch 1985, pp. 54, 80.

46 Following the war, Ohsawa wrote Naze Nihon wa Yabureta Ka (Why was Japan Defeated?) analyzing Japan's defeat through issues of food and nutrition and discussing Japan's necessary political, social and economic reforms.

${ }^{47}$ Kotzsch 1985, pp. 119-39.

48 Later nineteenth century figures Mizuno Nanboku and Hirata Atsutane repeated Kaibara's commonsense food knowledge in their work. On Kaibara, see Tucker 1989.
} 
Shindo fuji expressed the idea that human bodies represent the transformation of the natural world: soil, air, water and vegetation support human life. In practice, this saying meant that people should eat things available where they live, an early articulation of the contemporary local foods movement. Vegetables should ideally come from within 3 ri (approx. 7.3 miles). ${ }^{49}$ One should avoid produce that was grown in hothouses, chemically treated, genetically modified, or imported from thousands of miles away. To Western audiences, Ohsawa explained:

The world of life is governed by the law of God: shin do fu ji, meaning that the body and the land are not two (separated or divided). Whoever ignores this suffers just punishment sickness, deterioration, degeneration-because he cannot adapt to his surroundings... The healthy, happy man... must discover natural foodthat which grows in his immediate area- uncontaminated by ... pesticides, artificial fertilizers, preservatives and additives. ${ }^{50}$

The second aphorism, Ichibutsu zentai idealises an economical mindset. One should use the whole body of all natural foods. Vegetables should be used from roots to stem: the leaves of radishes and other vegetables can be pickled and vegetable peels can be used in soups. Grains should be eaten whole and rice unhulled. Japanese texts often mention how macrobiotics helps to decrease the household food budget because one need buy fewer ingredients and would no longer buy expensive items like meat, butter, and cream. ${ }^{51}$ These two golden rules, however, were undermined in the Western macrobiotic movement, because the directive to import and consume expensive and unfamiliar Japanese foods violated these very tenets.

A final form of nostalgia invoked by the re-importation of the Japanese traditional diet is its emphasis on clear gender roles, with women serving as professional housewives carefully planning meals, preparing cumbersome whole grains and pickling vegetables at home. Ohsawa had firm views on the roles and responsibilities of women. The family was the basic unit of the nation and its wellbeing depended on the mother's understanding of dietary needs. If she chose and prepared foods properly, the family would be strong and healthy and benefit society. Ohsawa recommended that mothers separate girls and boys from the age of seven so they could develop their feminine yin qualities and masculine yang qualities appropriately.

Ohsawa transmitted this gender ideology to the West, and it was adopted by liberal macrobiotic followers despite the feminist movement of the time.

49 Akiba 1997, p. 293.

50 Ferre (ed.) 1994, p. 14.

51 See for example Genmai 2006, p. 7. 
Critics of the diet attacked its 'extremely conservative gender ideologies' and claimed macrobiotics was anti-feminist, 'alienating Western women from their role as keepers of the family'. ${ }^{52}$ Despite such charges, in the communal left leaning macrobiotic houses established in the USA beginning in the 1960s, a married couple directed the house, with the wife responsible for cooking and the husband for mastering the philosophy. These gendered divisions were rationalised through the notion that women were more yin and this was better suited to preparing food. ${ }^{53}$ Others argued that, through calibrating their intake of yin and yang foods, macrobiotics could actually 'fine-tune their gender daily' and as a result had a fluid gender identity. ${ }^{54}$ Some contemporary Western cookbooks, however, continue to further reinforce gender ideology, essentialising gender characteristics with statements like 'meat-eating men may drink alcohol, making them remorseful, depressed thugs and chocoholic women may eat a chicken breast daily, making them hysterical control freaks' ${ }^{55}$

In its return to Japan in the last decade, one main audience for macrobiotic cookbooks is the epitome of gender ideology, the 'frugal housewife' who must simultaneously provide nutrition, please the family palate and run the home economically. Many Japanese texts naturalise this position and try to address the perception that feeding your family a macrobiotic regime is difficult, tasteless, time consuming and spartan-the very characteristics that appealed to some of the early countercultural adopters in the West. Japanese cookbooks give tips on how to make macrobiotics fun and tasty for the entire family, even if this means occasionally using taboo ingredients like eggs, honey or fish stock.' ${ }^{56}$

Despite the separation I've posited between culinary tourism in the West and culinary nostalgia in Japan, contemporary works on macrobiotics identify emerging convergences in Japanese and Western motivations. Macrobiotics is still quite new to Japan, but it has already reached a third generation of Western leaders who are far less concerned with culinary tourism, perhaps because ingredients that were once rare, like miso and seaweed, are now commonplace. They tend to de-emphasize Eastern philosophy and focus instead on health, beauty and convenience. Simon Brown, a student of Ohsawa's disciple Michio Kushi, omits the yin-yang terminology altogether referring to these qualities simply as acidity and alkalinity. Brown focuses on convenience and

52 Crowley 2002, p. 38.

53 Alexander 1972.

54 Crowley 2002, p. 38.

55 Porter 2004, p. 267.

56 Okada 2007. 
reduces the need for long-term commitment, providing ten-minute meals, tips for eating out, one-day plans, and three-day detoxification regimes. ${ }^{57}$ This trend is also apparent in current Japanese literature promoting 'weekend' macrobiotics. ${ }^{58}$ Macrobiotic columns in Japanese gourmet magazines urge beginners to just dabble by trying an easy recipe or two, with 'no need to be an eager enthusiast'. ${ }^{59}$ While the latest Western texts tend to downplay specific health claims, generally claiming that the diet promotes general good health and has helped some people to recover from illness, Japanese texts often retain claims of miraculous cures, sometimes presenting case studies of physical and psychological conditions improved by the diet or cases of increased radiance and physical beauty. ${ }^{60}$

One text that demonstrates an increasingly consumerist attitude in Western macrobiotics is Jessica Porter's Hip Chick's Guide to Macrobiotics. Porter emphasizes how macrobiotics provides a youthful appearance and better sex while still allowing self-indulgence. Her website claims 'You don't have to trade in your Manolos for a pair of Birkenstocks' in order to be macrobiotic. ${ }^{61}$ She mentions A-list celebrities like Madonna and Gwyneth Paltrow who are macrobiotic. Other celebrities whom the media have associated with the diet include Demi Moore, John Travolta, Boy George and reality-TV star Kim Kardashian. A narcissistic rather than touristic motivation for becoming macrobiotic seems central among the wave of celebrities as media reports about celebrity adoption of the diet rarely, if ever, mentions any association with Japan or the diet's underlying yin-yang philosophy.

As noted in the introduction Japan has its own macrobiotic hip chicks, young fashionable women with discretionary income who are consumers, or one might say tourists, rather than whole-hearted adherents of the strict dietary regime. They sample wares at upscale restaurants, like the six outlets operated by Chaya Macrobiotics, including one in the high-end Isetan department store in Shinjuku. Chaya is a self-described casual, French-style restaurant. It serves fish, vegetable curries and tempeh croquettes alongside an array of macrobiotic desserts like strawberry cream cakes, brulees, tarts and even birthday cakes for young women, who, it is popularly believed, adore all sweet treats. If one is in a hurry, a Chaya takeout counter is available. One can even order Chaya products online.

57 Brown 2005.

58 See for example Tomikawa 2006 and Genmai 2006, p. 15.

59 Hashimoto 2008, pp. 28-9.

${ }^{60}$ Okada 2007, pp. 55-70. Perhaps this is due to Japan's reputation as a less litigious society than the U.S.

${ }^{61}$ http://www.hipchicksmacrobiotics.com/, accessed 17 July 2009. 
Western macrobiotic adherents often take pride and pleasure in a strict and puritanical attitude towards food consumption. Ohsawa taught them that when beginning macrobiotics their cooking would probably not taste good and their meals would not be well balanced. In contrast, contemporary Japanese cookbook authors try to find ways to enjoy their favorite types of foods while on a macrobiotic diet. Several Japanese cookbooks are dedicated to desserts and sweets made without eggs, milk products or refined flour or sugar. ${ }^{62}$ Another focuses on recipes that go well with sake. ${ }^{63}$ Ironically, some describe how to use Japanese traditional ingredients to make favorite Western dishes like gratins and pastas. ${ }^{64}$

Today, macrobiotics has reached a size and critical mass in Japan that it never really held in the West. Eating macrobiotic has been made more mainstream and viable through the recent proliferation of macrobiotic food stores and cooking classes. The proclaimed use of domestic organic vegetables by fast food chain Mos Burger and the advent of Natural Lawson, a branch of a major national convenience store that focuses on organic, natural food, demonstrates that the macrobiotic style of eating has truly reached mass audiences, although not in the strict and philosophical fashion intended by Ohsawa.

\section{Conclusion}

In its journeys across the oceans and back from the 1950s to the twenty-first century, macrobiotics has calibrated its messages and held different appeals for a range of audiences. In the late 1950s and 1960s, during Japan's high-speed economic recovery, the most receptive audience for Ohsawa's religiouslyinfused brown rice regime was the West, particularly the USA. During this era, there was a convergence of Cold War Orientalism, the term Christina Klein has applied to the cultural fascination with Asia in American popular culture, with a rising counterculture seeking opportunities to reject mainstream beliefs and lifestyles, whether Christianity or Jello, in favor of Eastern philosophy and natural foods. ${ }^{65}$

Ohsawa cannily played upon Orientalist longings to enhance the attractions and credibility of his dietary philosophy. Macrobiotics gained momentum, despite critiques by doctors, dieticians and disgruntled ex-followers. Ohsawa died in 1966, but his disciples Michio Kushi and Herman Aihara

\footnotetext{
${ }^{62}$ See for example, Garcia de Paredes 2007 and Issei 2006.

63 Nakaji 2009.

${ }^{64}$ Okada 2007, pp. 47-9.

65 Klein 2003.
} 
continued to operate centers in Boston and California and the movement grew, with an estimated 10,000 followers in major American cities in 1972 and thousands more in Europe. ${ }^{66}$ A network of macrobiotic businesses including restaurants, food companies and bookstores helped to sustain the movement and it began to reach broader mainstream audiences in the 1980s, as the mass media publicised the diet as a potential cure for cancer.

As Japan began to realize the high regard the West held for this form of Japanese traditional cuisine, it rose in the Japanese consciousness and estimation. Its emerging popularity was due, in no small part, to this endorsement by the West, as aptly illustrated in the title of a 2006 book World Acknowledgement of the Wisdom of Japanese Cuisine: The Story of Macrobiotics (Sekai ga mitometa washoku no chie: makurobiotikku monogatari). ${ }^{67}$ Ohsawa had realized early that Western acclaim would be an important factor in macrobiotics' eventual success in Japan. In 1973 he complained to Japanese audiences about the lack of popularity of his diet in Japan in comparison with the West. In Tokyo he had only fourteen or fifteen students and the primary customers for macrobiotic stores were foreigners. But in Belgium, crowds for his talks were immense and in Brussels alone there were ten stores and three restaurants. $\mathrm{He}$ bragged of the new macrobiotic city in America: Chico, California, and compared the seriousness and dedication of Western macrobiotics to famous Japanese figures like Fukuzawa Yukichi who aided the rapid spread of Western learning and philosophy in the early Meiji period. ${ }^{68}$

While the primary audiences tended to differ during macrobiotics' introduction in the West and Japan, i.e. hippies vs. housewives, the messages of recently published books in Japanese and English seem to be converging. Both sides of the Pacific now focus on the convenience and consumerism that pervade contemporary life, on how macrobiotics produces youth and beauty with little sacrifice or inconvenience. There is no longer need for pseudo-religious or long term commitment. Other non-Western health regimes such as yoga and Ayurveda have likewise been secularised, appropriated by Western gurus as systems for physical beauty rather than spiritual benefit, in order to enhance their mass consumer appeal. ${ }^{69}$ Given both his astute marketing abilities and his spiritual commitment, it is difficult to guess whether George Ohsawa would have been disappointed or proud.

66 Alexander 1972.

${ }^{67}$ Mochida 2005.

68 Sakurazawa 1973, 'preface'. Originally published without cited preface in 1938.

69 See for example, Selby 2005, pp. 120-31. 


\section{References}

Abrams, N. 2008, 'More than One Million Mothers Know it's the Real Thing' in K. Lebesco and P. Naccarato (eds), Edible Ideologies: Representing Food and Meaning. Albany: SUNY Press, 105-35.

Aihara, H. 1985, Basic Macrobiotics, Tokyo: Japan Publications Inc.

Akiba R, 1997, Tennokei no shokutaku washoku ga sodateta nihonjin no Kokoro, Tokyo: DHC.

Alexander, G. 1972, 'Brown Rice as a Way of Life' New York Times, 12 March 1972, 87-98.

Alter, J. 2005, 'Introduction: The Politics of Culture and Medicine,' in J. Alter (ed.), Asian Medicine and Globalization, Philadelphia: University of Pennsylvania, 1-6.

Appadurai, A. 1988, 'How to Make a National Cuisine: Cookbooks in Contemporary India', Comparative Studies in Society and History, 30: 1, 3.

Brown, S. G. 2005, Modern-day Macrobiotics: Transform your Diet and Feed your Mind, Body and Soul, Berkeley: North Atlantic Books.

Caldwell, M. 2006, 'Tasting the worlds of Yesterday and Today: Culinary Tourism and Nostalgia in Post-Soviet Russia' in R. Welk (ed.), Fast Food/Slow Food: Cultural Economy of the Global Food System, New York: Rowman \& Littlefield, 97-113.

Crowley, K. 2002. 'Gender on a Plate: The Calibration of Identity in American Macrobiotics' Gastronomica, 2, 3: 37-48.

Cwiertka, K. J. 2006, Modern Japanese Cuisine: Food, Power and National Identity, London: Reaktion Books.

Dufty, W. and N. Sakurazawa, 1965, You Are All Sanpaku, New York: University Books.

Ekken, K. 1974, Yöjökun: Japanese Secrets of Good Health. Tokyo: Tokuma Shoten.

Elliott, C. 'Consuming the Other: Packaged Representations of Foreignness in President's Choice' in K. Lebesco and P. Naccarato (eds), Edible Ideologies: Representing Food and Meaning. Albany: SUNY Press, 220-43.

Fernandez-Armesto, F. 2001, Civilizations: Culture, Ambition, and the Transformation of Nature, New York: Free Press.

Ferre, C. (ed.) 1994, Essential Ohsawa: From Food to Health, Happiness to Freedom, New York: Avery.

Gabaccia, D. 1998, We Are What We Eat: Ethnic Food and the Making of Americans, Cambridge: Harvard University Press.

Garcia de Paredes, P. 2007, Tamago mo gyunyu mo shirozato mo tsukawanai Patorishio no happi makurobiotikku suitsu. Tokyo: Shohan.

Genmai de ochaku daietto: shimpuru makurobiotekku, 2006, Tokyo: Orenjipêji mook.

Hashimoto, A. 2008, 'Makurobiotikku na hitotoki' Bishoku Gochiso, 28-9.

Hooks, B. 1999, 'Eating the Other: Desire and Resistance' in S. Nagy Hesse-Biber, C. K. Gilmartin and R. Lydenberg (eds), Feminist Approaches to Theory and Methodology: An Interdisciplinary Reader, New York: Oxford University Press.

Issei, N. 2006, Makurobiotikku de itsumo no okazu \& dezato Tokyo: Gurafusha.

Ishige, N. 2001, The History and Culture of Japanese Food, London: Kegan Paul.

Ishizuka S. 1898, Tsuzoku Shokumotsu Yojoho, ichimei, kagakuteki shokuyo taishinron. Tokyo: Hakubunkan.

1975 [1897], Kagakuteki shokuyo chöjuron, Tokyo: Nippon C.I.

Kingsbury, C. M. 2008, 'Food Will Win the War: Food and Social Control in World War I Propaganda' in K. Lebesco and P. Naccaroto (eds), Edible Ideologies: Representing Food and Meaning. Albany: SUNY Press, 53-72.

Klein, C. 2003, Cold War Orientalism: Asia in the Middlebrow Imagination, 1945-1961 Berkeley: University of California Press. 
Kotzsch, R. E. 1985, Macrobiotics Yesterday and Today, Tokyo: Japan Publications Inc.

Kushi, M. 1977, The Book of Macrobiotics, Tokyo: Japan Publications.

— 1983, Your Face Never Lies, Wayne, NJ: Avery Publishing Group.

1982, The Cancer Prevention Diet, New York: St. Martin's Press.

2004, [1985], The Macrobiotic Way: The Definitive Guide to Macrobiotic Living, New York: Penguin.

LeBesco, K. and P. Naccarato (eds) 2008, Edible Ideologies: Representing Food and Meaning. Albany: SUNY Press.

Long, L. (ed.) 2004, Culinary Tourism, Lexington: University of Kentucky Press.

Matsumoto I. 1976, Shokuseikatsu no Kakumeiji: Sakurazawa Yukikazu no Shisō to Shōgai, Tokyo: Chisan Shuppan.

Mochida K. 2005, Sekai ga mitometa washoku no chie: makurobiotikku monogatari, Tokyo: Shinchosha.

Nakaji, 2009, Osake o tanoshimu hito no tame no kantan makurobiotikku reshipi, Tokyo: Yosensha.

Okada, K. 2007, Raku raku makurobiotikku kyōshitsu, Tokyo: Nittō Shōin.

Ohsawa, G. 1994 [1928], Ishizuka Sagen: denki Ishizuka Sagen, Tokyo: Ozorasha.

1972 [1931], Le Livre des Fleurs, Paris: Vrin.

— 1931, Le Principe Unique de la Philosophie et de la Science d'extreme Oriente, Paris: Vrin. 1936, Muso Genri, eki: jitsuyō benshōhō, Tokyo: Sakurasawa Joichi Sensei Chosaku Kankokai.

1976 [1941], Ningen no Chitsujo. Tokyo: Nippon C.I.

1975 [1942], Seimei Genshō to Kankyō, Tokyo: Nippon C.I.

- 1947, Naze Nihon wa Yabureta ka, Ohtsu City Japan: Musō Genri Kenkyūjo.

1952, Le Livre du Judo, Paris: Centre Ignoramus de Paris.

1959, Zen Macrobiotics: The Art of Rejuvenation and Longevity, Los Angeles: Ohsawa Foundation.

— 1966, The Philosophy of Oriental Medicine: Book of Judgment, Los Angeles: Ohsawa Foundation.

—_ as Sakurazawa Y. 1973, Shokuyo jinsei dokuhon: makurobiotikku kenko to kofuku no jinsei sekkei, Tokyo: Nihonshakaikyoku.

Porter, J. 2004, The Hip Chick's Guide to Macrobiotics: A Philosophy for Achieving a Radiant Mind and Fabulous Body, New York: Avery.

Sattilaro, A. 1982, Recalled By Life, Boston: Houghton Mifflin.

Sawada, J. A. 2004, Practical Pursuits: Religion, Politics and Personal Cultivation in Nineteenthcentury Japan, Honolulu: University of Hawaii Press.

Selby, M. A. 2005, 'Sanskrit Gynecologies in Post-Modernity: The Commoditization of Indian Medicine in Alternative Medical and New Age Discourses on Women's Health' in J. Alter, (ed.) Asian Medicine and Globalization, Philadelphia: University of Pennsylvania, 120-31.

Tomikawa S. 2006, Shumatsu dake de suru makurobiotikku, Tokyo, Bunkasha.

Tucker, M. E. 1989, Moral and Spiritual Cultivation in Japanese Neo-Confucianism: The Life and Thought of Kaibara Ekken, 1630-1740, Albany: SUNY Press. 